\title{
Fluency: A Review of Developmental and Remedial Practices
}

\author{
Melanie R. Kuhn \\ Rutgers, The State University of New Jersey
}

\author{
Steven A. Stahl \\ University of Georgia
}

\begin{abstract}
The authors review theory and research relating to fluency instruction and development. They surveyed the range of definitions for fluency, primary features of fluent reading, and studies that have attempted to improve the fluency of struggling readers. They found that (a) fluency instruction is generally effective, although it is unclear whether this is because of specific instructional features or because it involves children in reading increased amounts of text; (b) assisted approaches seem to be more effective than unassisted approaches; (c) repetitive approaches do not seem to hold a clear advantage over nonrepetitive approaches; and (d) effective fluency instruction moves beyond automatic word recognition to include rhythm and expression, or what linguists refer to as the prosodic features of language.
\end{abstract}

The process of becoming literate can be conceptualized as a series of qualitatively different stages through which learners progress as they become increasingly proficient with print (Chall, 1996b; Harris \& Sipay, 1990). One of the primary advances in this process involves the shift from dealing with words on a word-byword basis to a rapid, accurate, and expressive rendering of text. In other words, learners develop such familiarity with print that they achieve fluency in their reading. Fluent reading may underlie or assist in effective engagement with text (LaBerge \& Samuels, 1974). The purpose of this article is a review of the literature examining how children move toward fluent reading. It will incorporate both theoretical discussions and practical studies relating to fluency research. Specifically, to accomplish this purpose, we have reviewed the theoretical accounts of reading that include an important role for fluency in the reading process and studies that have attempted to facilitate its development.

\section{Stages of Reading Development}

Although a number of stage models have been proposed, we will focus on Chall's (1996b) stages of reading development because they provide a comprehensive view of the reading process as well as a strong theoretical underpinning for the view of fluency that will be presented here. Chall's (1996b) model is a broad one, and it will be useful to focus more specifically on the growth of word recognition as well. As such, the description of stages presented here will be followed by a brief outline of Ehri's (1995, 1998) phases of sight-word learning and the contribution that automatic word recognition makes to fluent reading.

Melanie R. Kuhn, Graduate School of Education, Rutgers, The State University of New Jersey; Steven A. Stahl, Department of Reading Education, University of Georgia.

Correspondence concerning this article should be addressed to Steven A. Stahl, who is now at the Department of Curriculum and Instruction, University of Illinois at Urbana-Champaign, 395 College of Education, 1310 South Sixth Street, Champaign, Illinois 61820. E-mail: sstahl@ uiuc.edu
Chall (1996b) proposed six stages through which readers proceed, each of which emphasizes a particular aspect of reading development. The first is an early reading or emergent literacy stage. This period encompasses the literacy behaviors that are developed prior to formal instruction. That is, the learner develops a foundation that will allow for later instruction to proceed in a meaningful manner. For example, children develop insights into the reading process that include concepts about print, phoneme awareness, and book-handling knowledge. Further, they come to recognize that print represents language and carries the story's message. However, it is important to note that the exact nature of what a child learns prior to formal instruction is highly dependent on the sociolinguistic community and culture in which he or she participates. Next comes the initial stage of conventional literacy or the beginning of formal reading instruction. At this stage, the instructional emphasis is on developing learners' recognition of basic sound-symbol correspondences while providing them with sufficient opportunity to establish their decoding ability.

Following this is a period called confirmation and fluency or "ungluing from print" (Chall, 1996b, p.18) in which readers confirm what is already known to develop their fluency. Having established their accuracy in decoding during the previous stage, learners must now develop their automaticity with print. Further, as their reading becomes increasingly less halting, they develop the ability to represent what is read in ways that imitate natural or conversational tones. In other words, they are able to make use of prosodic features such as appropriate phrasing, stress, and intonation in their reading. Once a learner has established this level of comfort with print, it is easier to construct meaning from a text than when he or she still struggles with word identification. This stage is the focus of this review.

During the next stage, there is a precipitous shift in the amount of expository text with which students are presented. In fact, in the majority of school systems in the United States, students move from reading for enjoyment to reading for instruction. Chall (1996b) called this stage of development "reading for learning the new." The focus of the curriculum shifts to the understanding of content-area material, and students are expected to gain proficiency with increasingly complex texts. However, throughout this 
period, much of the information is presented from a single perspective, often by way of introduction to a subject.

As students acquire a solid base of knowledge in a given area, they are increasingly likely to be exposed to a number of sources on that subject. This stage incorporates what Chall (1996b) referred to as "multiple viewpoints." It is here that readers begin to deal with a variety of viewpoints regarding a given topic, and learners are expected to critically evaluate these sources. The final stage in Chall's (1996b) model is that of "construction and reconstruction." It is during this stage that an individual begins to synthesize the myriad of viewpoints presented in texts to determine his or her own perspective on a given subject, a skill that is essential if a learner is to develop into a critical reader.

\section{Confirmation, Fluency, and Ungluing From Print}

According to Chall's (1996b) model, after the learners have established a basic familiarity with sound-symbol correspondences, there is a need for young readers to focus on automatizing their decoding ability. This period of development is not for the learning of new skills, "but for confirming what is already known to the reader" (Chall, 1996b, p.18). Such practice allows learners to gain comfort with print, thereby enabling the transition from learning to read to reading to learn (Chall, Jacobs, \& Baldwin, 1990) to proceed smoothly. Without such automatic processing, students will continue to expend a disproportionately large percentage of their attention on decoding, which in turn leaves them with an inadequate amount for comprehension (Adams, 1990; LaBerge \& Samuels, 1974; Stanovich, 1980, 1984). In other words, fluency is a prerequisite if learners are to succeed at the primary purpose of reading, the construction of meaning from text (Allington, 1983; Samuels, 1988; Schreiber, 1980).

\section{Phases of Sight-Word Development}

Embedded within the decoding and fluency stages, children seem to go through a series of phases as they develop automaticity of sight-word reading. We are defining sight words as did Ehri (1995) - as all words that have been recognized accurately on several occasions (i.e., words that are in one's instant recognition repertoire), rather than the more common definitions of either words with irregular spellings or words that are recognized as a result of their visual features or a particular method of instruction. Ehri (1995) suggested that words become sight words through a thorough analysis of the word's orthographic structure. The resulting mental representation enables a reader to access the word quickly and automatically. She further argued that, on each additional encounter, the sight of such words triggers the memory of these words in the learner. This identification includes information about the word's spelling, pronunciation, and meaning. However, the establishment of a complete representation does not occur immediately. Instead, Ehri proposed that such a full depiction occurs in four distinct phases: prealphabetic, partial alphabetic, full alphabetic, and consolidated alphabetic.

The prealphabetic phase corresponds to Chall's (1996b) early reading stage. During this phase, beginning readers remember sight words by making connections between certain visual attributes of a word and either its pronunciation or its meaning (e.g., the tail at the end of the word $\operatorname{dog}$ or the two eyes in the middle of the word look). It is considered to be prealphabetic because lettersound relationships are not involved in the recognition process. Although this can be an effective strategy as long as the number of words encountered remains low, it becomes increasingly ineffective as the number of sight words increases.

Following the visual cue phase, there is a shift to the second phase, that of partial alphabetic recognition. At this point, students begin to read sight words by making the connections between some of the letters in written words, usually the initial and/or final letters because of their salience, and their corresponding sounds. The advantage here is that the alphabetic system is available to aid in word recognition. This phase is enabled both by knowledge of letter names and a certain amount of phonological awareness (Stahl \& Murray, 1998). Because readers at this stage lack a full knowledge of the spelling system and the ways in which to segment and match phonemes and graphemes, this form of sightword recognition remains incomplete.

As learners continue to develop an understanding of the alphabetic system, they move toward full alphabetic coding. This parallels the initial stage of conventional literacy in Chall's (1996b) model. At this point, readers recognize how most graphemes represent phonemes in conventional spelling. This allows readers to easily recognize different words with similar spellings (e.g., bat, bait, and brat) because each word's representation is sufficiently complete. It further enables them to read new words by determining how the unfamiliar spellings will be pronounced. However, although learners at the full alphabetic phase can decode words, those words that are encountered sufficiently often become sight words. As such, recognition is immediate. Such immediate recognition also occurs for those words that are phonetically irregular and therefore not decodable using sound-symbol correspondence rules.

During the final phase, the consolidated alphabetic phase, the learner comes to recognize letter patterns that occur across different words as units; this becomes part of their generalized knowledge of the orthographic system. This final advance reduces the memory load for the reader, makes it easier to learn new words, and speeds up the process of word recognition by increasing their awareness of the ways letters co-occur in the spelling system. This final phase of sight-word development ensures the learner establishes automatic and accurate word recognition that is integral to the reading process.

Perfetti (1992) argued that readers may need to proceed through these phases of development with every word to assure that each is processed accurately and automatically. The final phase of word recognition corresponds with the confirmation and fluency stage of Chall's (1996b) model. Such accuracy and automaticity are essential components of fluent reading, however, we will argue that they are necessary but not sufficient conditions for fluency.

\section{Fluency as a Factor in the Reading Process}

Given that the ultimate goal of reading is the construction of meaning (Anderson, Hiebert, Wilkinson, \& Scott, 1985), it is important to assess the role fluency plays in comprehension. There are two primary theories regarding fluency contribution to a reader's understanding of text, each of which emphasizes one of fluency's component parts. The first, and better known of the two 
theories, stresses the contribution of automaticity to fluent reading, whereas the second focuses on the role of prosody.

There seems to be a consensus regarding the primary components of fluency: (a) accuracy in decoding, (b) automaticity in word recognition, and (c) the appropriate use of prosodic features such as stress, pitch, and appropriate text phrasing. When reviewing the theories relating to fluency's role in the overall reading process, it is important to tease out the various ways these components may contribute to a learner's ability to interpret text. There is a rich literature about the contribution of accurate word recognition to reading comprehension (Johns, 1993) and enjoyment of reading (Nell, 1988). This will not be reviewed here. Instead, we will concentrate on the relative importance of automaticity and prosody to comprehension.

\section{Contribution of Automaticity}

Proficient readers have certain features in common; they not only read accurately, their recognition of words is automatic. The question is "How does this automaticity contribute to the primary goal of reading, comprehension of text?" An individual has a limited amount of attention available for any given cognitive task (LaBerge \& Samuels, 1974; Perfetti, 1985; Stanovich, 1980). This being the case, attention expended on one activity is, necessarily, attention unavailable for another.

In the case of reading, an individual is required to perform at least two interdependent tasks; the reader must determine what words comprise the text while simultaneously constructing meaning. As such, the greater the amount of attention expended on decoding, the less that is available for comprehension. To ensure that readers have enough attention to understand texts adequately, the argument continues, it is necessary for them to develop decoding to the point where each word is recognized instantaneously. Once this occurs, they will have the necessary attention to focus on the sense or meaning of the text.

According to Stanovich's (1980) interactive-compensatory model, information from multiple sources is available for aiding readers in their construction of meaning. This is true at each stage of development and presumes that learners will make use of information from orthographic, phonological, semantic, and syntactic sources. However, if a reader is less adept at gleaning information from one source, he or she may become overreliant on other sources. It follows that, until readers achieve automaticity in word recognition, they will necessarily depend more on alternative knowledge sources to make sense of what is being read. In other words, they are more likely to rely on context as an aid to word recognition and comprehension than are fluent readers. (This refers only to the use of context as an aid to identifying words already in a child's lexicon, not to the use of context in learning new word meanings. Stanovich [1980] would argue that automatic word recognition allows readers to concentrate on the meaning of text, rather than on identifying words. Thus, automatic word recognition allows one to focus contextual analysis on constructing meaning, rather than decoding [see also Adams, 1990].)

The question then becomes how do learners make the shift from decoding accurately but deliberately to decoding automatically? According to the automaticity theorists, the best way to ensure this transition is through extensive practice. As with any skill that requires an individual to coordinate a series of smaller actions to create a unified process, it is practice that allows the learner to develop expertise. In terms of reading, this practice consists primarily in providing successive exposures to print. As letters, and later words, become increasingly familiar to the learner, less and less attention needs to be directed toward processing text at the orthographic level. This ability to complete a process without conscious attention fulfills LaBerge and Samuels's (1974) criterion for automaticity. In this way, the automaticity theory accounts for two of the components of fluent reading, accurate decoding at a sufficient rate. It further posits an explanation for automaticity's role in text comprehension. However, there is an important aspect of fluency that this theory does not attend to, that of prosody.

\section{Contribution of Prosody}

Although the automaticity theory accounts for the accurate and effortless decoding that fluent readers exhibit, it fails to provide a sufficient explanation for the role prosody plays in the reading process. When an individual provides a fluent rendering of a text, there is a tacit understanding that he or she is doing more than simply reading the words quickly and accurately; he or she is also reading with expression. Implicit in the phrase reading with expression is the use of those prosodic features that account for the tonal and rhythmic aspects of language (Dowhower, 1991).

Prosody comprises a series of features including pitch or intonation, stress or loudness, and duration or timing, all of which contribute to an expressive rendering of a text (Allington, 1983; Dowhower, 1991; Schreiber, 1980, 1987, 1991). Additionally, prosodic reading includes appropriately chunking groups of words into phrases or meaningful units in accordance with the syntactic structure of the text. Taken together, these features are classified as suprasegmental because they extend over more than one speech sound and contribute to meaning. Given this understanding of what constitutes prosody, it is necessary to determine the role prosody plays in the development of fluency and the ways in which these features contribute to the construction of meaning from a text.

Prosody may provide a link between fluency and comprehension. Chafe (1988) speculated that, to read a sentence with intonation, one must assign syntactic roles to the words in the sentence. The assignment of syntactic roles is a key component of microprocessing, or the mental parsing of a text into hierarchically ordered propositions (Kintsch, 1998). Schreiber (1987) also suggested that the explicit presence of prosodic cues may be one crucial difference between speech and reading and one of the reasons that speech is easier to understand. However, Schreiber (1987) reported that the evidence supporting a link between prosody and microprocessing is weak, with some studies finding links between the use of prosodic features and syntactic comprehension and others failing to find such an effect.

Dowhower (1991) identified six distinct markers that comprise prosodic reading: pausal intrusions, length of phrases, appropriateness of phrases, final phrase lengthening, terminal intonation contours, and stress. From a linguistic perspective, readers who uses these markers appropriately are capable of making the connection between written and oral language. In other words, they are able to transfer their knowledge of syntax from speech to text by effectively applying these features to their reading. Such readers can produce a rendering of text that maintains the important 
features of expressive oral language in addition to reading it accurately and at an appropriate rate.

Children who have not achieved fluency read either in a wordby-word manner or by grouping words in ways that deviate from the type of phrasing that occurs naturally in oral language (Allington, 1983; Chall, 1996b; Clay \& Imlach, 1971; Dowhower, 1991; Samuels, 1988). Young children are highly attuned to the use of prosodic features in speech (Dowhower, 1991; Schreiber, 1987; Schreiber \& Read, 1980). In fact, research indicates that infants under a year old use prosodic features as a primary cue to the syntactic structure of their language and that their babbling follows the characteristics inherent in the prosody of their primary language. Further, Read and Schreiber (1982) and Schreiber (1987) have determined that children are not only highly attuned to prosodic elements in oral language but that they are actually more reliant on them for determining meaning than are adults.

Given children's sensitivity to prosody in oral language, it seems reasonable to assume that they are equally dependent on these features in determining the meaning of text (Allington, 1983; Dowhower, 1991; Schreiber, 1991). In fact, appropriate phrasing, intonation, and stress are all considered to be indicators that a child has become a fluent reader (Chomsky, 1978; Rasinski, 1990b; Samuels, Schermer, \& Reinking, 1992). The reasoning behind this emphasis is that such readings provide clues to an otherwise invisible process; they act as indicators of the reader's comprehension. Given that a fluent reader is one that groups text into syntactically appropriate phrases, this parsing of text signifies that the reader has an understanding of what is being read.

\section{Research on Fluency Instruction}

One approach to examining the relative effects of automaticity and prosody to the development of fluency and comprehension is to examine the instructional research. The National Reading Panel (NRP; 2000) conducted an examination of the instructional literature in two areas related to fluency-guided oral reading and independent silent reading. They defined guided oral reading as approaches that involve having the student read with guidance and feedback. Included in this definition were common approaches such as repeated reading, impress reading, paired reading, shared reading, and assisted reading. Independent silent reading involved providing time for children to read by themselves, such as sustained silent reading, drop everything and read, and so on. The NRP's thorough examination of the PsycINFO and ERIC databases found 364 unique articles, with 77 articles meeting their methodological criteria. The 14 studies on the effectiveness of independent silent reading did not provide conclusive evidence that the approach improved reading achievement. Krashen (2001), however, criticized the methodology behind this finding, suggesting that there were many studies about independent silent reading that the NRP did not include and was concerned that the NRP overemphasized certain studies in their narrative review.

Consider four groups of studies not included. Anderson, Wilson, and Fielding (1988) had 155 fifth graders keep logs of their out-of-school activities. They found that the amount of time spent reading was the best predictor of gains in reading achievement. Taylor, Frye, and Maruyama (1990) similarly had 195 fifth and sixth graders keep daily logs of their reading in and out of school. They found that reading in school, but not reading at home, contributed significantly to gains in reading achievement. These two studies were correlational and, thus, were not included in the NRP (2000) corpus. Elley (2000) reported a number of studies of "book floods" or giving children large amounts of high interest texts. He reported that book floods lead to significant gains in English literacy when compared with a control. Although these studies examined English literacy, the participants were nonEnglish speakers, thus making these studies ineligible for inclusion. Another source of support for the effects of reading volume comes from a series of studies conducted by Stanovich, Cunningham, and their colleagues. Cunningham and Stanovich (1991, 1998), for example, used a children's literature Title Recognition Test to assess the amount of exposure that elementary school children had to print. They found that print exposure had significant impacts on children's fluency and other aspects of reading skill, even when general ability is controlled. Again, this study is correlational. Taken together, this body of evidence is strong support for the importance of practice in reading on reading achievement.

The NRP (2000) found an overall effect size of 0.41 for guided oral reading, with effect sizes on individual measures ranging from 0.55 on measures of reading accuracy to 0.44 on measures of reading fluency to 0.35 on measures of reading comprehension, all of which were significantly different from 0 . We have reviewed the studies in their corpus and found them to be a mixture of a number of different types of oral-reading practice. In shared reading, a teacher would read a big book to a class repeatedly, encouraging the children to take greater responsibility for reading with repetition. In repeated reading, the child reads the passage as a whole, with the teacher monitoring and providing feedback. In other approaches, the child reads the passage once. In one study, the guidance was provided before reading. In short, the studies reviewed by the NRP were so wide ranging that one can only draw the broadest of conclusions about the effectiveness of fluencyoriented instruction from their meta-analysis.

We will restrict our discussion to a few different approaches used to improve children's fluency. Among these are approaches primarily used with clinical populations or children with reading problems, such as repeated reading (Samuels, 1979) and assisted reading (Chomsky, 1978; Heckelman, 1969, 1986), and approaches used with entire classes, such as the oral recitation lesson (Hoffman, 1987) and fluency-oriented reading instruction (Stahl, Heubach, \& Cramond, 1997). There have been other studies that attempted to improve children's speed of word recognition in isolation (e.g., Fleisher, Jenkins, \& Pany, 1979-1980) and approaches that segmented text to enable children to identify pausal units in the text (e.g., O'Shea \& Sindelar, 1983). We will use these studies to inform our knowledge of the issues related to fluency development.

To obtain a large corpus of studies relating to instructional approaches to fluency development, we first undertook a search of both the ERIC and the PsycLIT databases for any articles that referred to reading fluency. As we began to locate these articles, we either read through the abstract or briefly scanned the article to confirm that the contents were appropriate for further review and analysis. In addition, if the article was to be included, the reference list was used as a means of cross checking references. In this way, we were able to locate a number of articles that were not identified in the initial search. The articles that emerged from this search 
process fell into four broad categories: theoretical bases of fluency development, research pertaining to the validity of these theories, recommendations for classroom practice, and intervention studies. Given our purpose, we chose to concentrate on intervention studies to determine the overall effectiveness of fluency instruction.

When deciding whether a given article should be included as part of this review, we had both inclusionary and exclusionary criteria. We selected studies that focused on evaluating strategies designed to promote readers' fluency development, such as the development of either the automaticity or prosodic components of fluent reading or some combination of the two. Methods and representative studies are presented for each type of intervention, along with a summarization of the results.

We chose not to consider articles that dealt with either externalor self-correction strategies because such studies focus on components of the reading process that lead to more effectively attending to the text rather than on a fluent rendition of the reading (e.g., Mudre \& McCormick, 1989). Nor did we include studies that focused exclusively on training accurate word recognition. It is reasonably well established that teaching children to be more accurate at recognizing words leads to improved comprehension (e.g., Chall, 1996a).

We intended to conduct a meta-analysis, but did not, for three reasons. First, we found relatively few studies with control groups. Baseline studies can be submitted to meta-analytic techniques (e.g., Scruggs, 1987), but these studies cannot be combined with control group studies. Two separate analyses are more likely to be confusing than enlightening. Second, the effect sizes we calculated fluctuated widely, from 0.13 to 2.79 . High effect sizes are likely because of a lack of variance in the control condition, leading to exaggerated estimates of effect. These few effect sizes over 1.00 would have to be eliminated from the analysis to avoid their having an excessive influence on the calculated effect. Finally, there were a number of different conditions used as controls, from no treatment to having the students spend an equivalent amount of time in nonrepetitive reading. These different control conditions made it difficult to come up with a common metric, as should be done in a meta-analysis. Instead, we used vote-counting procedures to analyze the data, combined with qualitative synthesis of the studies themselves.

\section{Studies}

We found 58 studies dealing with assisted reading, repeated reading, or classroom interventions designed to improve fluency. In addition, we found nine studies dealing with segmented text and four studies dealing with speeded isolated word recognition. This is a total of 71 studies.

Segmented text and isolated word recognition studies were analyzed separately. Our logic in doing so was as follows: If fluency-based instruction affects microprocessing, then we might also expect to find effects in studies using segmented text, that is, text broken up by phrases. If fluency instruction improves comprehension by helping students develop automatic word recognition, then we might see similar effects from studies in which readers' word recognition was speeded up through practice of reading words in isolation (see Table 1).

There are several reasons for the preponderance of studies without control groups. Repeated reading and assisted readings
Table 1

Studies With and Without Control Groups

\begin{tabular}{lccc}
\hline \multicolumn{1}{c}{ Approach } & Control group & No-control group & Total \\
\hline Repeated reading & 15 & 18 & 33 \\
Assisted reading & 7 & 8 & 15 \\
Classroom intervention & 4 & 6 & 10 \\
Total & 26 & 32 & 58 \\
\hline
\end{tabular}

were developed as clinical approaches for working with children with reading problems (e.g., Dahl, 1979). Thus, testing their effectiveness with targeted children using baseline or multiple baseline designs is appropriate. In other cases, researchers compared different variations of repeated reading (Rashotte \& Torgesen, 1985). In another case, students involved in a pilot study made so much gain as to make a control group seem to be unethical (Stahl et al., 1997).

Authors who used baseline designs did test for statistical significance, but the lack of studies with a control in this literature as a whole is problematic. Baseline designs are useful in evaluating the effectiveness of approaches for children who are in small, heterogeneous populations, such as learning-disabled children or children with reading problems. There is an assumption in such designs of a null hypothesis in which the child would make no growth over the period of instruction. This may be tenable in the case of children with severe reading problems but not tenable with a more average population. Chomsky (1978) illustrated this point. She used a set of taped readings to bring children with reading problems to fluent reading, finding significant improvement over time. But this improvement was equivalent to 6 months over a 10 -month school year. Thus, her students, although ahead of where they started, were further behind their classmates. Similarly, in Blum et al.'s (1995) study, although all children made significant progress, only 1 of the 5 children used in the study progressed beyond the preprimer level during the 19 weeks of the intervention. Neither result would be the accelerated progress needed by children who are behind their classmates in reading (Clay, 1993).

\section{Fluency Instruction as Remediation}

The studies of fluency instruction were in two overarching categories, those that build on independent learning, or what Dowhower (1989) labeled unassisted strategies, and assistedreading strategies that provide learners with a model of fluent reading behaviors. Further, these studies consist of two types of interventions, those that dealt with fluency training as a means of remediation for individuals and those designed for classrooms. Additionally, researchers looked at a range of indicators to determine reading improvement, including measures of accuracy, rate, prosody, and comprehension. The studies are categorized here, first, according to the type of intervention provided and, second, in terms of whether their reading methods were designed for individual learners, dyads, or groups. We discuss both near transfer, that is, improvement on fluency measures such as increased reading rate on previously unread texts, and far transfer, for example, improvement in comprehension on new material. 


\section{Unassisted Repeated Reading}

Perhaps the best known of the reading interventions designed to support fluency development is that of repeated reading. This is a strategy that relies on independent practice of text. The basic method of repeated reading was developed by Samuels (1979) and Dahl (1979) in an attempt to apply LaBerge and Samuels's (1974) automaticity theory to practice. Samuels (1979) and Dahl noted that classroom practice often consists of students reading new text on a daily basis in the hope that they will improve their wordrecognition skills. However, it struck them that, by increasing the amount of practice on a given passage, students might be able to improve not only their accuracy but their fluency as well. Growth in fluency was to be measured through the establishment of a speed criterion that, if effective, should lead to an increase in reading rate.

They developed a process in which students were required to read a 100-word passage repeatedly until they reached the criterion rate of 100 words per minute (wpm). An initial reading rate of between 35 and $50 \mathrm{wpm}$ was deemed appropriate for the first reading of the passage. Should the learner read outside these initial wpm guidelines, the passage difficulty would be adjusted, and the student would be placed with material at a higher or lower reading level. Similarly, if a student made an excessive number of miscues in a given passage, difficulty levels would likewise be adjusted. Students were expected to read the passage orally to an adult, then reread the passage silently, keeping track of the number of rereadings. On completion of a given number of practices, they were asked to reread the passage orally. Students' accuracy and reading rates were expected to improve until they achieved a predetermined criterion.

Dahl (1979) first tested this approach in a study designed to evaluate three reading strategies, training in the use of hypothesis testing (the active use of context to predict the identity of unknown words), repeated reading, and isolated word recognition. The study consisted of 32 struggling second-grade readers randomly assigned, 4 to a treatment group. Dahl reported that both the hypothesis testing and the repeated-reading conditions, as well as the interaction of the two, produced significant gains on a measure of reading rate and on a traditional cloze test. Additionally, the repeated-readings training significantly reduced the number of miscues made. No significant effects were found favoring the isolated word condition.

Given that Samuels's (1979) and Dahl's (1979) original goal was to develop a procedure that would allow for increases in reading rate as well as in the improvement of learners' accuracy, the method of repeated reading proved successful. In fact, the success of the method led to the recommendation of its use as a remedial reading strategy. Samuels (1979) modified the method so that passages of 50 to 200 words could be used and established a more flexible wpm criterion rate, dependent on the learner's grade level and reading level placement, while continuing to stress speed over accuracy. He also presented it as an effective strategy for improving not only fluency, here defined as automaticity in word recognition (Samuels et al., 1992), but also for comprehension. According to automaticity theory, freeing readers' attention from decoding and allowing focus on the content of the passage should improve the construction of understanding.
Given the initial success of this method, it was used with both average and learning-disabled children. We found a total of 33 comparisons dealing with repeated reading, over half of the total population of studies dealing with fluency reading instruction. These studies are summarized in Table 2 . The vast majority dealt with either students at the second- or third-grade level or older children with reading problems who could be presumed to be reading at a primary level. Thus, researchers generally appeared to target their work toward students in Chall's (1996b) confirmation and fluency stage.

\section{Effects of Repeated Reading on Fluency and Comprehension}

We found 15 studies that assessed the effects of repeated reading on fluency using a control group. We did a vote count (Light $\&$ Pillemer, 1984) of these studies, vote counting in two ways. First, we counted each study once, using the majority of comparisons to assign it depending on whether there was evidence of repeated reading effectiveness. In six studies, repeated reading produced significantly greater achievement than the control; eight studies had no such an effect, and, in one, repeated reading improved fluency for familiar passages but not for a transfer passage. In the second vote-counting procedure, we counted each individual comparison. This procedure gave added weight to studies with multiple comparisons. In eight comparisons, the repeatedreadings group performed significantly higher than the control, whereas 21 comparisons did not. Overall, repeated reading did not produce significantly greater achievement than a control. However, this may be the result of the type of control group involved. In some cases, students were assigned to a no-treatment control group, whereas, in others, students were expected to read equivalent amounts of connected text as the intervention group but not in a repeated manner (e.g., Mathes \& Fuchs, 1993; Rashotte \& Torgesen, 1985). As will be discussed later in the article, the two types of controls are likely to produce very different outcome measures.

Criteria. The majority of studies had students read each passage a set number of times, usually three readings, rather than using the criterion suggested by Samuels (1979; i.e., $100 \mathrm{wpm})$. Of the 15 studies with a control group, 2 used criteria. Of these 2, 1 had a significant treatment difference and 1 did not. Of the remaining 13 studies in which students read a set number of times, 3 found significant differences, 9 did not, and 2 studies had mixed findings. Overall, there were too few studies that used a criteria to evaluate its effectiveness.

Difficulty. We also examined the relative difficulty of the passages. It could be argued that having students read and reread relatively easy passages would improve their fluency (e.g., Clay, 1993). It could also be argued that the rereadings scaffold children's word-recognition abilities so that they can read more difficult material.

Mathes and Fuchs (1993) compared the use of easy and difficult materials and found no effect for the difficulty of materials. However, they also failed to find a difference between a repeatedreading treatment and a control group. Rashotte and Torgesen (1985) used relatively easy reading materials and also failed to find significant differences between their repeated-readings treatment and a control group. The remainder of the studies used materials at 
or above the child's instructional level. Six out of the 11 remaining studies found differences favoring the treatment group. Our best guess is that more difficult materials would lead to greater gains in achievement, but more research is needed on this question.

Comprehension. As noted in Table 2, the basic results for comprehension mirror those for fluency. Generally, where an increase in fluency was found, there was also an increase in comprehension. The exceptions were in Carver and Hoffman's (1981) study and Dahl's (1979) study, in which there were effects for microcomprehension (generally cloze) measures but not for more general comprehension measures (such as standardized tests). This is consonant with the notion that fluent reading would affect the reader's microcomprehension processes, through the assignment of syntactic relations in sentences, but might not affect macrocomprehension processes, which are more affected by prior knowledge and more global comprehension strategies (see Stahl, Jacobson, Davis, \& Davis, 1989). It also may be that the more general measures of comprehension, such as standardized achievement tests, are more resistant to change.

Other findings. Dowhower (1987) not only used rate and accuracy as measures of fluency but also found that repeated reading had measurable effects on speech pauses and intonation. Herman (1985) found not only effects on speech pauses and rate for read material but also that repeated-readings treatment transferred to previously unread material.

Rashotte and Torgesen (1985) found that students reading texts with a high overlap of words improved in rate and accuracy better than students reading texts with a low overlap. Although these two groups differed significantly, neither was significantly more fluent than a group engaged in nonrepetitive reading. However, Rashotte and Torgesen limited students to four readings of each text; they might have found stronger effects had they had students read a fluency criterion for each text.

\section{Assisted-Reading Strategies}

As with the unassisted repeated reading, assisted readings emphasize practice as a means of improving accuracy, automaticity, and prosody as well as the learner's understanding of a text. Further, they provide extensive exposure to print. However, unlike traditional repeated reading, assisted-reading methods provide learners with a model of fluent reading (Dowhower, 1989). There is also a greater amount of variation amongst the different intervention strategies. To maintain a sense of cohesion, we will outline the various methods along with several studies that evaluate the effectiveness of these methods.

We found 15 studies involving assisted reading. Of these, 7 had a control group to evaluate effectiveness of the treatment, and 8 did not. These studies are summarized in Table 3.

Neurological impress method or assisted reading. Heckelman (1969) suggested the neurological impress method as a remedial strategy for disfluent readers, although the term may go back further. Its name reflects a naiveté about neurology-it was supposed to impress the words directly into the student's "brain." Nowadays, this notion, and the name, seems quaint, at best. However, the underlying method is still used in practice. Currently, it is called assisted reading or even choral reading, because a tutor and tutee read the same material chorally. The method requires the teacher and student to read simultaneously and at a rapid rate. The student sits in front of the teacher, both hold the book, and the teacher reads into the student's ear. The teacher slides a finger under the words and can vary the pace so that sometimes the reading is louder and faster and sometimes it is slower and softer. This joint reading continues until the teacher notes the student is becoming tired or uncomfortable. Although some of the research followed this exact procedure, other studies varied in their application of the format.

Heckelman (1969) used the technique with 24 seventh through tenth graders, all of whom were at least 3 years behind their grade level in reading. Instructors worked with students using the assisted-reading strategy for $15 \mathrm{~min}$ a day, 5 days a week, for a maximum of $7.25 \mathrm{hr}$ as part of a remedial summer program. Students selected their own material but were encouraged to use relatively easy material at first before graduating to more difficult selections as they became increasingly fluent. Although not all students made "substantial" (Heckelman, 1969, p. 281) improvements, the mean gain was 1.9 years. That is, the instructional strategy improved the students' oral reading fluency and their comprehension on a standardized measure of reading comprehension. Similar results were found in other case studies (e.g., Langford, Slade, \& Burnett, 1974; Mefferd \& Pettegrew, 1997).

Although assisted reading is quite successful in improving the reading fluency of struggling readers, Hollingsworth (1970) recognized the time-consuming nature of the procedure. Given the requirement of one-on-one teacher support for the method, it was feasible for assisted reading to be used primarily in tutoring situations but did not provide a viable approach for integration into most traditional classrooms. As such, Hollingsworth (1970) redesigned the procedure so that it could be used with up to 8 students simultaneously. By using a wireless system, children could listen to a tape recording of a text while allowing the teacher to monitor their reading. To test this modification, Hollingsworth (1970) randomly selected 8 fourth graders reading at grade level and 8 controls matched to these students on the basis of their scores on a standardized reading test. There were no significant differences on any measure between the students who participated in the assisted reading procedure and those who did not. However, none of the students who took part in the study, either as controls or in the intervention group, were considered to be struggling readers. Rather, they were reading on grade level and were, therefore, unlikely to benefit greatly from fluency instruction (Chall, 1996b). In fact, Hollingsworth (1970) considered the students' ability to read at grade level the most likely explanation for the seeming ineffectiveness of the intervention. As such, he decided to replicate the study using a different population.

For his second study, Hollingsworth (1978) selected 20 fourth-, fifth-, and sixth-grade students identified by their school district as remedial readers. The students were randomly selected and assigned to either the assisted-reading or control condition. The wireless system allowed 10 students to listen to taped recordings of the passages simultaneously. Hollingsworth (1978) further increased the number of sessions from 30 to 62 . Beyond this difference, the investigation was similar to his first study (Hollingsworth, 1970). This time, however, there was a significant treatment effect on the standardized comprehension test. In real terms, students using the assisted-reading technique made 1 year's growth over the course of a semester, whereas the other students made only 0.04 year's growth during the same period. For students 


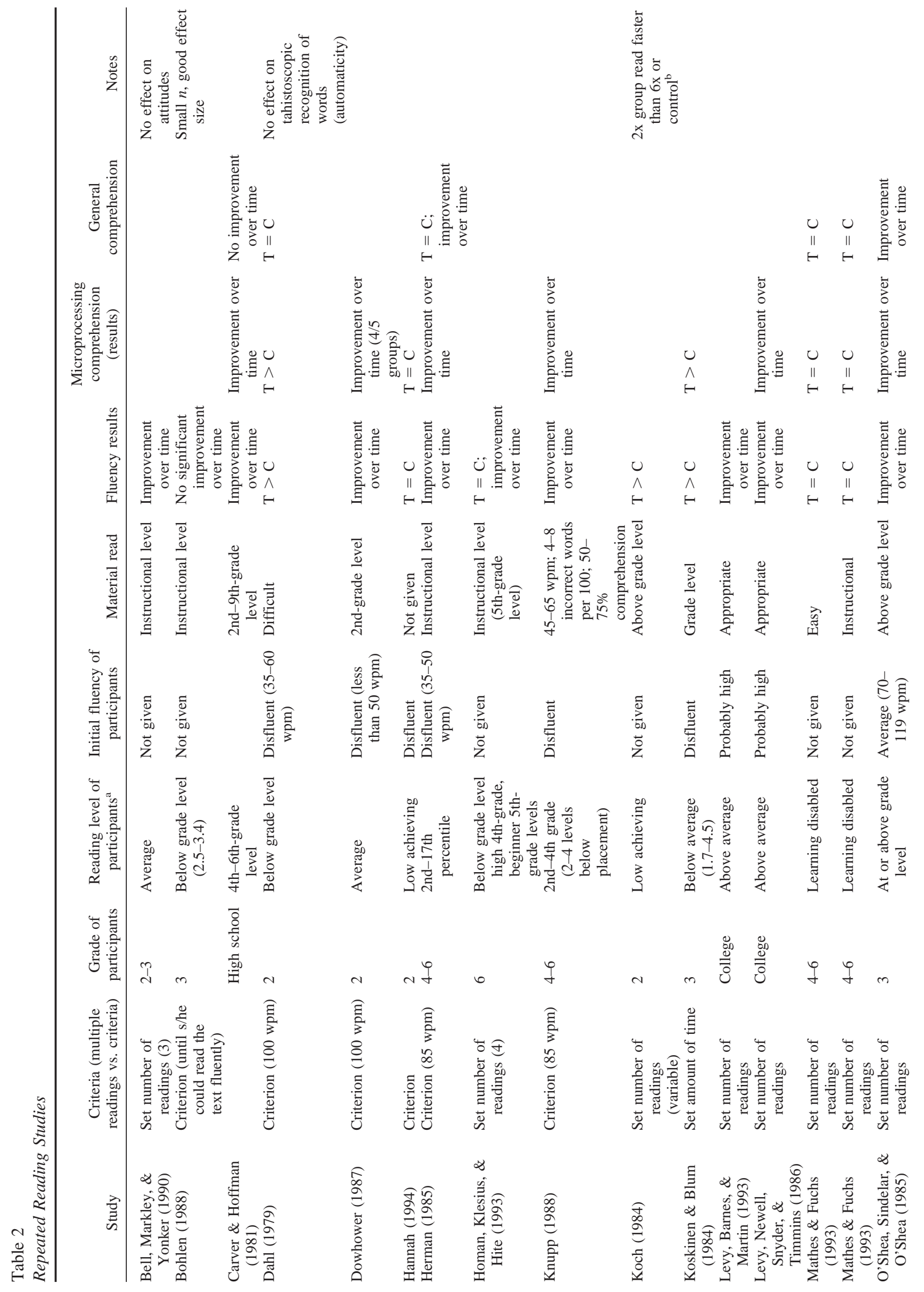




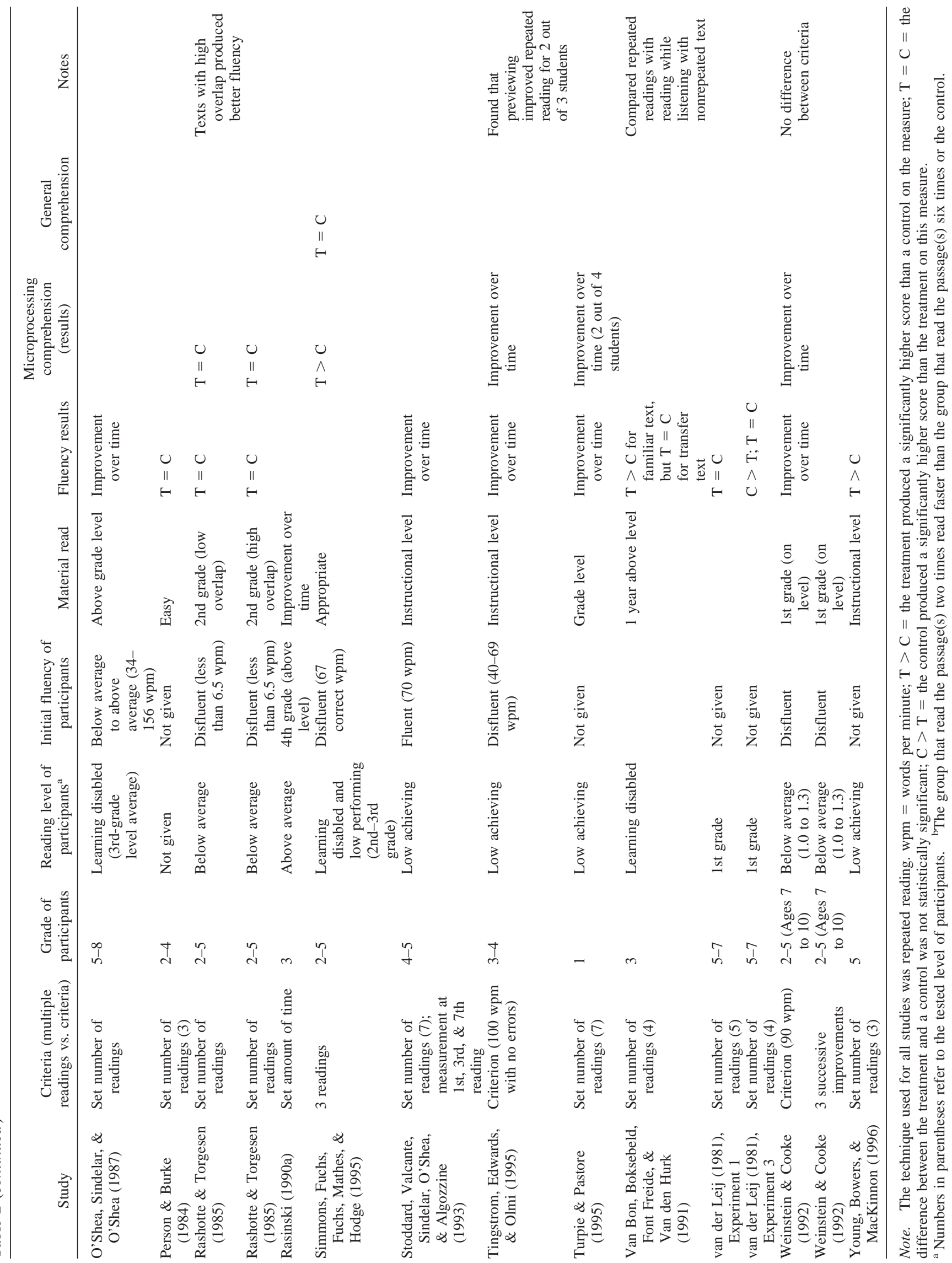




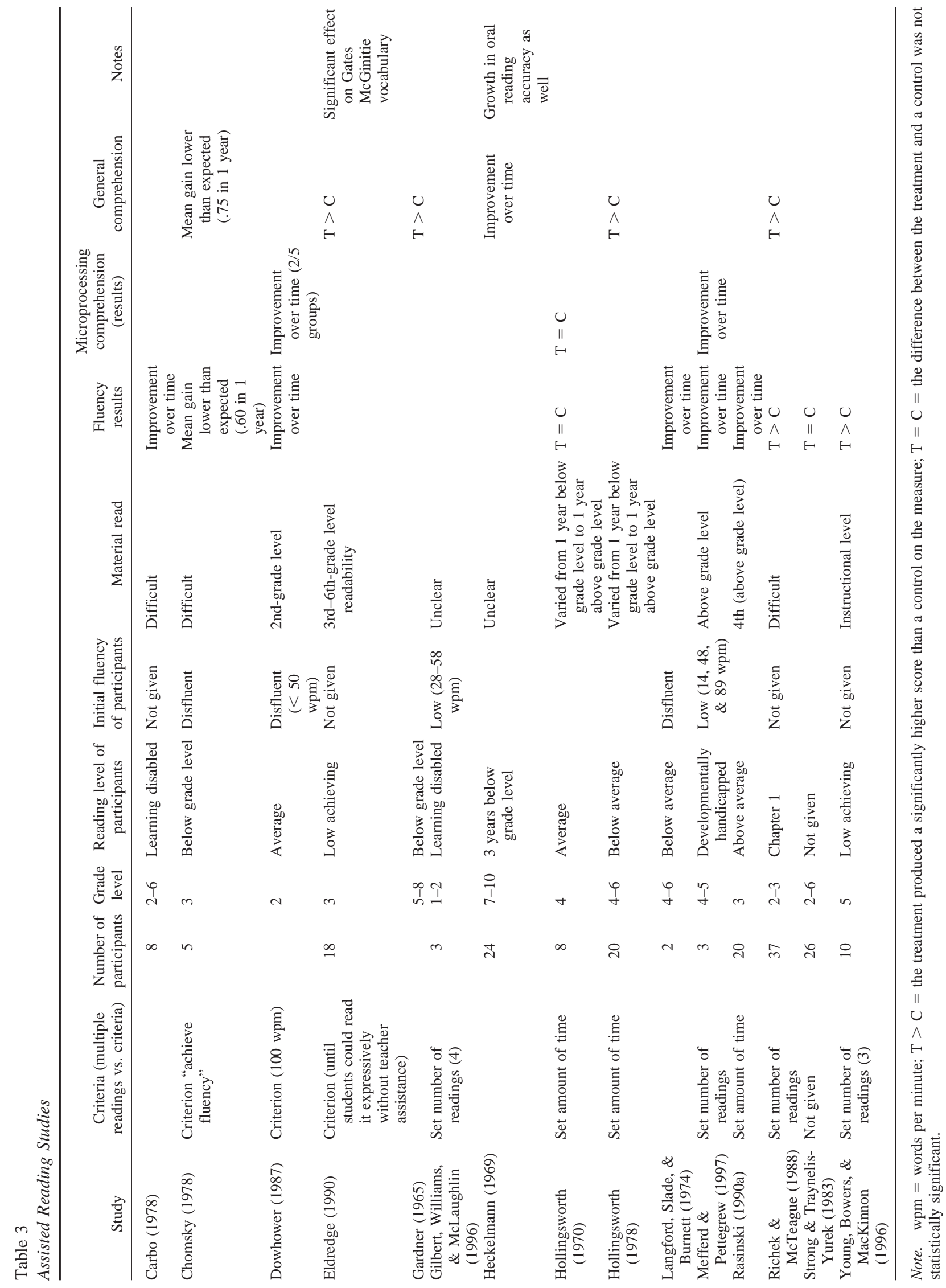


identified as remedial readers, assisted readings was effective in promoting fluency and comprehension development, at least as measured by standardized test scores. However, these gains did not generalize to students who were already fluent readers.

Reading-while-listening. Chomsky (1978) and Carbo (1981) also used tapes for an assisted-reading approach called readingwhile-listening. Chomsky worked with 5 eight-year-olds who were identified by their teacher as struggling readers. Although all 5 children, 2 girls and 3 boys, had extensive instruction in decoding strategies, they seemed unable to apply their knowledge to connected text. Each of these children was reading 1 to 2 years below their grade level in January of third grade, and all professed an intense dislike of reading. Chomsky felt that the most important aspect of any successful intervention for these students would, by necessity, expose them to significant amounts of print while making that print accessible to them. To achieve this goal, she made available on tape two dozen books ranging in reading level from second to fifth grade. (The tapes were originally developed to teach English to Japanese students.) The children were asked to listen repeatedly to the books until they were able to render the text fluently. The children selected their own books and set their own pace for the assisted repeated reading. They were instructed first to listen to an entire book or chapter from a book before selecting a portion that they wanted to practice. They were then to read along while repeatedly listening to those parts of the story they wanted to rehearse. In addition, Chomsky and a research assistant worked with each child on a weekly basis both to monitor progress and to engage the learner in further analysis of the text through language games.

Initially the process was slow and the children had some difficulty coordinating their eye movements with the voices on tape. If they lost their place, they were instructed to return to the beginning of the passage, but, as they became increasingly familiar with their texts as well as the process, it became easier for them to keep track of the story. Four of the children took approximately 20 listenings over a month-long period to become fluent with their selection, although 1 child achieved fluency over the course of 2 weeks. Further, each subsequent selection took the learners less time, until by the fourth or fifth book (or for 1 child, the third chapter), students were achieving fluency with their text in approximately 1 week. Perhaps even more telling, however, was the fact that, according to both parents and teachers, the children were reading independently and were willing to engage in writing activities as well. In addition, all students demonstrated growth on the posttest measures administered as part of the study, although averaging only a 6-month gain in fluency and a 7.5-month gain in comprehension over the course of 10 months. This may have been a greater gain than they had made in previous years, but it still is not accelerated progress (Clay, 1993).

Carbo (1978) used a slightly modified approach in a read-along procedure. Her tapes stressed phrases. Children were instructed to slide their fingers along under the words as a form of tactile reinforcement, and each page was cued to minimize the chances that the listeners might lose their place. She worked with 8 learning-disabled children over the course of 3 months using these individualized recordings. During this period, she reported that the students gained 4 to 15 months in word-recognition ability, with the average gain being 8 months.
These two studies differ from Hollingsworth's (1970, 1978) modified assisted-reading approach insofar as there was less direct monitoring from the teacher, and students were responsible for determining the length and frequency of their sessions. One of the primary concerns regarding such read-along techniques is that there was no way to ensure active engagement on the part of the learners. Indeed, in a number of classroom observation studies (e.g., Evans \& Carr, 1985; Leinhardt, Zigmond, \& Cooley, 1981), time spent listening to tapes in class did not significantly affect achievement. In these reading-while-listening studies, however, students were held responsible for being able to read the text fluently, so that they did actively participate in the process. Further, students seemed both to enjoy the taped stories and to display pride in their abilities and their success.

There were several differences between the Carbo (1978) and Chomsky (1978) studies. First, Carbo (1978) used specially developed tapes in which the stories were read slowly, with cues to turn the page. Chomsky used commercially available taped stories, recorded at ordinary conversational speed. The materials in Carbo's (1978) tapes were chosen to be difficult but not too far away from the child's ability. Chomsky did not measure their difficulty, but her taped stories were probably well above the children's reading level.

Carbo (1978) reported an average gain of 8 months in word recognition in 3 month's time; Chomsky (1978) reported average gains of 6 months in 10 months time in fluency and 7.5 months in comprehension. Chomsky's results reinforce our caution about accepting results of improvement over time. Although her students made a significant improvement, it was less than ordinarily expected as normal progress. Thus, her students were actually further behind their peers at the end of their treatment than they were before beginning it.

Closed-caption television. Rather than designing material that needed to be used in conjunction with a television monitor, Koskinen, Wilson, and Jensema (1985) made use of the closedcaption option available on a number of television programs with remedial readers in an exploratory study. Ten clinicians taught 35 second through sixth graders in a summer reading clinic. Although part of the lessons revolved around making predictions based on plot development and discussions of figurative-language use, students were also expected to practice short portions of the script to develop fluent renderings of the text. Selected programs included Sesame Street, Scooby Doo, and sitcoms. Because the study was exploratory in nature, no statistical measures were provided. However, many of these "turned off learners" (Koskinen et al., 1985, p. 5) not only enjoyed the lessons but felt they benefited from the strategy. The clinicians considered the lessons effective in promoting the learners' fluency.

Overall, using the same vote-counting procedure as for repeated reading, five of the seven studies, with a control group using assisted reading, had significant treatment differences. When analyzed by number of comparisons, six of the nine comparisons proved significant treatment effects.

Comparisons of assisted and unassisted repeated reading. Dowhower (1987) and Rasinski (1990b) looked at the effectiveness of both repeated reading and reading-while-listening on the development of reading fluency. Dowhower (1987) examined the effects of repeated reading on second graders at a transitional stage of reading development, that is, learners who were in the process 
of shifting from accurate but deliberate decoding to fluent reading. In designing the intervention, Dowhower (1987) chose to look at repeated reading and a reading-while-listening procedure to determine the effectiveness of these strategies in promoting fluency on measures of rate, accuracy, comprehension, and prosody. Further, she looked at these measures on both practiced and unpracticed text as well as across a series of passages. Her primary goal was for the students to reread a meaningful passage until their oral production was "fluid, flowing and facile" (Dowhower, 1987, p. 390).

Students were randomly assigned either to the assisted condition in which they worked with a tape-recorded model or to the unassisted condition in which they worked independently but were able to request assistance on difficult words. For the read-along conditions, students were encouraged to practice with the tape until they were comfortable with their reading, after which they were to continue practicing without the tape. Materials consisted of six basal stories with an early second-grade reading level rewritten to maximize equivalency. Students were assessed on rate, accuracy, the number of rereadings necessary to reach a $100 \mathrm{wpm}$ criterion, and their literal comprehension. In addition, a microcomputer was used to determine changes in students' prosody, assessing the following features: pausal intrusions or inappropriate hesitations within words or syntactical units; the length of phrases or number of words between pauses; appropriate phrasing or the use of syntactically and/or phonologically acceptable phrases; phrase final lengthening in which the last stressed syllable is longer than it would be if the word was located elsewhere in a phrase; and intonation or the appropriateness of the rise-fall patterns that occur at phrase boundaries, within the sentence, and at terminal markers.

Both forms of repeated reading produced significant increases in word accuracy and comprehension from the first to the last reading of the first half of the passage. Gains in reading rate also occurred on the second half of all passages and reached significance for three of the five stories. There was also evidence of minimal gains in accuracy from the practiced to the unpracticed portion of the passages, however, this was significant only for one trial in the assisted-reading condition. Additionally, comprehension gains were significant in two of the five trials for the assisted group and four of the five trials for the unassisted groups. Similarly, there were significant gains across readings for both groups on rate, accuracy, and for the assisted condition, in comprehension scores. Likewise, the number of rereadings it took for students to reach the criterion level significantly decreased across both conditions, and both groups had mean gains in rate and accuracy from the initial to the final test, all of which were significant. Further, the unassisted group's comprehension score had a mean gain as well. It is important to note that there were few shared words amongst the passages, but $77 \%$ of the words on the final test occurred in the stories.

There were slightly different results for the prosodic measures. Pausal intrusions lessened, and length of phrases increased significantly for both groups from the initial to the final readings of the stories as well as across readings. Additionally, the assisted group had significantly fewer inappropriate phrases from the initial to the final reading as well as across readings. Further, the assistedreadings condition significantly improved their intonation across readings, whereas the unassisted group's intonation improved significantly from the initial to the final readings of the passages. Finally, 8 of the 15 students demonstrated significant change in the lengthening of the final stressed syllable in a phrase. Overall, both forms of repeated reading were effective at improving rate, accuracy, and comprehension, and these gains transferred to similar but unpracticed passages. Further, these improvements increased over a series of passages. Although both strategies appear to be relatively equivalent on rate, accuracy, and comprehension measures, the reading-while-listening intervention had a more facilitative effect on the measures of prosodic development.

Following Dowhower's (1987) work, Rasinski (1990a) compared the effectiveness of repeated reading and reading-whilelistening on rate and accuracy. Twenty 3 rd-grade students were paired according to both teacher judgment of their reading abilities and their scores on a standardized reading test. As with Dowhower's (1987) research, students had significant gains in both reading speed and accuracy for both strategies, but no significant differences were reported between the two types of intervention. Given these findings, Rasinski (1990a) argued that, because both strategies appear to be equally effective and the reading-while-listening strategy was easier to implement, it may prove to be the more efficient aid in assisting readers' transition to fluency.

It is important to make a distinction between the reading-whilelistening used in these studies and listening centers commonly found in classrooms. In these interventions, students had to recite the readings and thus were held responsible for practicing the readings. In listening centers, there are often no criteria for the reading. If students are not held responsible, then they are unlikely to practice and thus unlikely to make gains. We note that classroom observational studies, such as those of Evans and Carr (1985) and Leinhardt et al. (1981), reported no effect on reading achievement for listening center activities.

\section{Classroom Approaches}

Two general approaches have been taken when attempting to adapt the principles of fluency instruction to the classroom. First, authors have tried to adapt clinical approaches directly. Assistedreading approaches, rather than unassisted repeated reading, have been adapted because of the need for social interaction to manage instruction in a classroom setting. Alternatively, authors have used a variety of techniques, such as echo reading, repeated reading, partner reading, and so on, in an integrated lesson plan. Both approaches show promise.

\section{Classroom Extensions of Assisted Reading}

Although the assisted-reading approaches outlined previously incorporate models of fluent reading as an aid to reading development, another alternative to the individual repeated reading involves the use of a partner as a means of facilitating fluency development. When the repeated-reading approach is modified so that 2 readers can work together, students are able to receive the type of immediate feedback that is not available when working on unassisted readings or prerecorded models. It is also a technique that can be effectively adopted in traditional classrooms.

Eldredge and Quinn (1988; Eldredge, 1990) examined a modified version of assisted reading (Heckelman, 1969) in which a classmate was chosen to be the lead reader. The struggling reader, known as the "assisted reader," received support and feedback from a partner. Pairs were changed weekly. The lead readers were 
selected on the basis of their ability to render the chosen texts fluently. They set the pace for the pair, read in phrases, and indicated each word as it was read. Five schools participated in the study, and second-grade classrooms were randomly assigned either to the dyad reading condition or to a control condition that made use of traditional basal reading groups throughout the course of the school year.

The assisted readers in the dyad classrooms read with partners until they reached the point where they could read grade-level material independently. At this point, they began reading on their own. Significant differences were found between the dyad and traditional basal groups on the vocabulary, comprehension, and total reading scores. Twenty-seven out of the 32 struggling readers participating in the dyad condition achieved scores at or above grade level, but only 6 of the 32 students (19\%) in the traditional basal group did so. As a result of the intervention strategy, students read with assistance material that would have been beyond their instructional level had they been working independently. Eventually, this led to independent reading of grade-level text.

Koskinen and Blum (1984) implemented a procedure that allowed for paired repeated reading of texts with below average third graders. Students in the repeated-reading condition worked in pairs where they learned to select their own texts, to follow the strategy, and to provide both self-evaluations and evaluations of their partners (the procedure is fully described in Koskinen \& Blum, 1986). Students in the repeated-reading condition not only significantly outperformed the students in a study activities condition, they made significantly fewer semantically inappropriate miscues.

Hoskisson and Krohm (1974) provided a transition from assisted readings to partner reading. Second-grade students were presented a series of tape-recorded stories at a read-along center. Tapes were prepared for a number of books; reading levels and pace of narration were adjusted to the individual reading abilities of students to assure that struggling readers did not get lost and better readers would remain engaged in the activity. Additionally, students were provided with weekly opportunities to read one of these stories to a peer. Children were partnered with students both at the same reading level and across reading levels. During this period, students performed the practiced text, and their partners provided any words that were not recognized. The slow readers became more confident in their renderings of a text, their reading rates increased, they made more frequent attempts and were more successful at identifying new words, their listening skills improved, and they appeared to derive more pleasure from their own reading. As with other forms of assisted readings, this version provided students with the opportunity to develop fluent reading behaviors in their presentation of connected text. Their lessons were extended to a home reading program.

Another effective way of encouraging students to read a text repeatedly is by giving them a real purpose for doing so. Such a purpose is provided by the cross-age reading strategy suggested by Labbo and Teale (1990). In this study, the authors invited fifth graders to read aloud to kindergartners from books that were appropriate for the younger participants. Twenty 5th graders experiencing reading difficulties were randomly assigned to one of three groups: cross-age readers, art partners in which the students worked with kindergartners on art projects, or a basal reading group in which students participated in their regular basal activities.
Students in the cross-age reading group were prepared for their reading performances in three ways. They were taught to select appropriate texts for their audience, they were given opportunities to develop fluency with the books, and they determined ways in which they could involve kindergartners in discussions of the texts. According to anecdotal evidence, not only did both the fifth graders and the kindergarteners enjoy their experience, 6 of the cross-age readers "were able to break poor oral reading habits" (Labbo \& Teale, 1990, p. 365) as a result of their repeated readings. Further, the cross-age readers made significant gains on a standardized reading measure and produced significantly higher scores than the other two groups.

We found two others studies that examined cross-aged tutoring but with less salutary results. Sutton (1991) examined the effects of cross-aged tutoring with first and second graders. She reported improvement over time in fluency and the amount of time spent engaged in reading, but she did not have a control group. Ramunda (1994) used above-average second graders as tutors, but she did not find a significant effect on comprehension compared with a control group.

It seems that cross-aged tutoring appears to be successful with below-grade-level tutors but does not seem to affect above-gradelevel tutors. This may be because the below-grade-level tutors in Labbo and Teale's (1990) study were reading relatively difficult materials, but the above-grade-level tutors in Ramunda's (1994) study were reading relatively easy texts. It could also indicate that the procedure aids fluency development in struggling readers but does not assist readers who are already considered to be fluent.

\section{Integrated Fluency Lessons}

Hoffman (1987) developed an oral recitation lesson (ORL) format as an alternative means of presenting a traditional basal reader story. The goal of the ORL was to use oral reading as a means of developing students' prosody, rather than treating it as a form of assessment. In this procedure, the teacher began by reading the basal story aloud. This reading was followed by a group discussion to deal with comprehension prior to the students' oral reading of the text. The teacher then reread the story, paragraph by paragraph, with the children following along and echoing back each paragraph. Next, the students chose or were assigned a portion of the text to master, with the understanding that their reading was to be expressive. They were provided with opportunity to practice this text until they could read it at an adequate rate with few errors ( 2 errors per 100 words). The final step involved the students reading their passage to the group before going on to the next story. Hoffman reported that the lessons were successful, but he did not present statistical data.

The effectiveness of the ORL was examined in two studies by Reutzel and Hollingsworth (Reutzel \& Hollingsworth, 1993; Reutzel, Hollingsworth, \& Eldredge, 1994). Both of these studies involved second graders. In the first study (Reutzel \& Hollingsworth, 1993), the oral recitation lesson was compared with a traditional round-robin-reading approach. Lessons lasted $30 \mathrm{~min}$ per day over 4 months, but because the teachers in the round-robin condition divided their classes into three ability groups, they worked directly with each group only $10 \mathrm{~min}$ per day. As a result, the ORL group may have had more teacher-directed reading time. The ORL was found to be superior on measures of fluency and 
experimenter-designed measures of comprehension but not on a standardized comprehension test.

For the second study (Reutzel et al., 1994), the ORL was compared with the shared-book experience (Holdaway, 1979). The shared-book experience consisted of the teacher's introduction of a story using a Big Book (a text enlarged so that it can be read by groups of children). This was followed by a discussion of the book and opportunities to reread the text as a group, in pairs, or independently. The lessons lasted $30 \mathrm{~min}$ a day for a 4-month period. The students in the shared-book experience produced significantly higher scores on the Word Analysis subtest of a standardized achievement test and on an experimenter-developed measure involving answering implicit questions. The ORL group, on the other hand, made significantly fewer oral-reading errors. There were no significant differences between the groups on measures of fluency, vocabulary, self-corrections, oral retelling, answering text-explicit questions, or the Comprehension subtest on the Standardized Achievement Test.

Eldredge, Reutzel, and Hollingsworth (1996) also compared the effectiveness of the shared-book experience and a round-robinreading approach with reading instruction over a 4-month period. The shared-book experience followed the format discussed previously, whereas the round-robin-reading lesson divided a 30-min period into three components. Ten minutes were spent reading the story in a round-robin manner with the teacher, $10 \mathrm{~min}$ were spent reading the text independently, and 10 min were spent reading it in pairs. In this case, the shared-book-experience group significantly outperformed the round-robin-reading group on every measure of word recognition, fluency, and comprehension.

Morris and Nelson (1992) created a program based on the ORL for a group of struggling second-grade readers. The goal was to incorporate the modeling of fluent reading along with the opportunity for practice into the student's reading lessons. The lessons took place for a 20 -min period, three times a week. On the first day, the teacher read a text aloud to the students and discussed the story with them. This was followed with an echo reading of the text. On the second day, students completed a paired reading of the text. The students then practiced a 100-word passage from the story until they could read it fluently with few errors. On the last day, the students read the passage they selected aloud while the teacher took a running record of the text. The intervention helped the children in one class develop word-recognition skills. However, Morris and Nelson did not use a control group, and whereas the students demonstrated growth on the ITBS, they were not reading at grade level according to that measure.

Rasinski, Padak, Linek, and Sturtevant (1994) used a similar format in their fluency development lesson; but instead of using basal reader stories, they used 50- to 150 -word texts. The researchers specifically suggested short texts so that the teachers were able to complete the entire lesson in a 15 -min session. In this way, the lessons could be incorporated into the current reading curriculum. Teachers read each passage aloud, students and teachers discussed the material then read the texts chorally, and students practiced reading in pairs. During the final component, the partners gave each other positive feedback. This intervention took place on a daily basis for a 6-month period, however, the only gains attributable to the treatment were in reading rate. These students were compared with children getting traditional literacy activities. Differences between the experimental treatment and the control in overall reading level, as measured by an informal reading inventory, were not statistically significant.

Another program based on Hoffman's (1987) work is the fluency-oriented reading instruction program (Stahl et al., 1997). This approach is an attempt to use repeated reading in a classroom program to develop fluent and automatic word recognition in second graders. The resulting program had three aspects-a redesigned basal reading lesson, a free-reading period at school, and a home reading program.

The redesigned basal reading lesson used the story from the children's second-grade reading text. This text would be difficult for children reading below grade level. With the support provided by the program, however, children who entered second grade with some basic reading ability could profit from a conventional second-grade text. The teacher began by reading the story aloud to the class and discussing it. This discussion put comprehension right in front, so that children were aware that they were reading for meaning. Following this, the teachers reviewed key vocabulary and did comprehension exercises and other activities around the story itself. Sometimes, this involved echo reading or having the teacher read part of the story and the class or a group echo it back. Other times, it involved having children read and practice part of the story. Then the story was sent home and read with the child's parents or other readers listening. For children who struggled, the story was sent home additional times during the week. Children who did not have difficulty with the story did other reading at home on these days.

The next day, the children reread the story with a partner. One partner would read a page while the other would monitor the reading. Then they would switch roles until the story was finished. Following partner reading, the teacher would do some extension activities and move onto another story.

Although this lesson was an important part of the program, it was not the only reading that children did. Time was set aside for children to read books that they chose each day. The children usually selected easy-to-read books that they read for enjoyment. Children sometimes read with partners during this period as well. The time ranged from $15 \mathrm{~min}$ in the beginning of the school year to $30 \mathrm{~min}$ by the end.

This program was carried out by four teachers in two schools during the first year and was expanded to 10 teachers in three schools for the second year. In both years, children gained, on the average, nearly 2 years in reading growth over the course of their second-grade year, as measured by an informal reading inventory. What was more gratifying were the effects that this intensive reading experience had on struggling readers. Over 2 years, all of the children but 2 who began the second-grade year reading at a primer level (out of a total of 105) or higher were reading at a second-grade level or higher at the end of the year.

In terms of the vote-count procedure, out of six studies that examined the effects of redesigned lessons designed to increase fluency, only three had a control group. Of the controlled studies, only one found clear evidence that the fluency-oriented lessons produced significantly better achievement than traditional instruction or a shared-book experience (which was commonly used in basal reading programs at the time). The effects of this instruction were suggestive, especially given the large gains reported by Stahl et al. (1997), but these approaches need to be examined in more controlled research. 


\section{Discussion}

When fluency instruction was compared with the traditional instruction used with a basal reader, fluency instruction improved children's reading fluency and comprehension. When different approaches to fluency instruction were compared, the results were less clear cut. Overall, these strategies seem, to a greater or lesser degree, effective in assisting readers making the transition to fluent reading. These include normally achieving students at the point where they are making this transition and those who are experiencing difficulties in becoming fluent.

This finding is subject to a caveat. Relatively few studies had conventional experimental or quasi-experimental designs. Many of the studies, from a special education tradition, used single or multiple baseline designs, in which progress is examined over a period of time. These studies can be robust (Neuman \& McCormick, 1995), but we find the reliance on this design in an entire body of research to be problematic. Also, in a number of studies in which progress could be compared with a norm, students' progress fell below what would be expected (e.g., Blum et al., 1995; Chomsky, 1978).

\section{Conclusions}

Fluency instruction and the stage model. According to Chall's (1996b) stage model presented at the beginning of this article, one would expect that fluency instruction would be most effective for children in the confirmation and fluency stage, from the end of first grade to third grade. This proposition is difficult to test because practically all studies used either normally achieving second graders or older children with reading problems who were reading at the second-grade level. That is, nearly all of the researchers working with fluency instruction implicitly accepted a stage view and acted accordingly. Of the few studies that used populations outside of this range, the results supported the stage model. Hollingsworth (1970) used average fourth graders, who should have been in the learning-the-new stage and not in need of fluency instruction and found that the treatment did not produce significant improvement over a control. Hollingsworth (1978) replicated this study with below-average fourth graders, who would have been predicted to benefit from this training, and found that they did. Stahl et al. (1997) found that their fluency-oriented reading instruction program was highly effective with children reading at a primer level or higher at the beginning of second grade. Nearly all of those students were reading at the second-grade level by the end of the year. With children reading below the primer level, the approach brought only half to that level. Teachers dropped children who were reading at an emergent stage from the program, because it did not seem to benefit them at all. Blum et al. (1995) found that only children who entered their assisted-reading treatment with some reading ability (a preprimer level) benefited from the treatment. Both Marseglia (1997) and Turpie and Pastore (1995) found that their repeated-readings treatment seemed to work better for the higher level first graders that they worked with than with the lower achieving first graders.

Therefore, the research results are consistent with the stage model. Fluency instruction seems to work best with children from between a late preprimer level and late second-grade level. Beyond or below that level, the results are not as strong. Children need to have some entering knowledge about words to benefit from rereading but not be so fluent that they cannot demonstrate improvements.

Effects of rereading. We stressed approaches that involved rereading of text, through assisted reading, repeated reading, or approaches that integrated a number of activities into a classroom lesson design. Although these approaches all seem to be effective, it is not clear why they are effective. Specifically, it is not clear whether these studies have their effects because of any particular instructional activities or through the general mechanism of increasing the volume of children's reading. Fluency instruction may work only by increasing the amount of reading children do, relative to traditional instruction. If so, then there may be other approaches that work as well or better. We know that increasing the amount of reading children do will improve their achievement (Anderson et al., 1988; Berliner, 1981; Taylor et al., 1990). Repeated reading and assisted readings may enable children to read more difficult material than they might otherwise be able to read or may provide a manageable structure to enable increased amounts of reading.

Several studies compared repeated and nonrepeated reading. Homan, Klesius, and Hite (1993); Mathes and Fuchs (1993); Rashotte and Torgesen (1985); and Van Bon, Boksebeld, Font Freide, and Van den Hurk (1991) found no difference in effects between repeated reading of a small number of texts and nonrepetitive reading of a larger set of texts. It is not the repetition that leads to the effect but the amount of time spent reading connected text.

We did not review the effects of paired reading, a nonrepeated assisted-reading approach (Topping, 1987; Topping \& Whitley, 1990). In paired reading, a more capable reader, usually an adult, works one-on-one with a struggling reader. A paired reading session begins with the tutor and tutee choosing a book together. The book need be only of interest to the tutee. There should be no readability limits (although our experience is that children rarely choose material that is far too difficult). They begin by reading in unison. The child signals the tutor, by touching the tutor or raising a hand or some other prearranged signal, when she or he wants to read solo. This continues until the child makes an error. Errors are corrected by the tutor's provision of the word. The pair then repeat the sentence in unison and continue reading. Paired reading has been used in the classroom and by parents. Morgan and Lyon (1979), for example, examined the effects of paired reading in the home. Over the 12 to 13 weeks during which children read with their parents, students made an average gain of 11.75 months in word recognition and 11.50 months in comprehension, with a range of 10-13 months. Thus, paired reading with parental support can be an effective way of developing the fluency of readers experiencing difficulty with connected text.

Because we did not find studies that directly compared paired reading with assisted reading and we did not have enough information to do a meta-analysis, we cannot say whether paired reading is more or less effective than assisted reading. Because paired reading does not involve repetition, although assisted reading does, this comparison would be useful in teasing out the effects of repetitive reading.

Relative difficulty of the text. What level should the text be on? Some have argued that having children read easy text improves fluency (e.g., Clay, 1993), but it seems that the most successful 
approaches involved children reading instructional-level text or even text at the frustration level with strong support (see Stahl et al., 1997). Mathes and Fuchs (1993), however, used both relatively easy and relatively difficult texts and found no effect for text difficulty. More directed work needs to be done to assess the effects of the relative difficulty of text on learning.

Next, both practice and support are essential to the development of fluent reading and can be provided either through repetition or modeling. Whether this provision comes through the use of taped narrations, another individual, or repetition seems to be less crucial a matter than the fact that it exists, for such support seems to allow learners to work within their zone of proximal development (Vygotsky, 1978), offering the scaffolding that allows learners to successfully move beyond the point at which they are able to work independently.

\section{An Irony}

The "method of repeated reading," as discussed by Samuels (1979, 1988; Samuels et al., 1992), was developed as an approach to translate LaBerge and Samuels's (1974) automatic information processing model into an instructional approach. LaBerge and Samuels's model is based on the notion that automatic processing of words will free up attentional resources that can then be devoted to comprehension. Samuels contended that through repeated reading, children would develop automatic word recognition, thus allowing them to be able to improve their comprehension. As shown in this review, repeated reading and other fluency-oriented approaches do improve comprehension. However, the irony is that they do not appear to improve automatic word recognition, as measured by conventional experimental psychology measures. Dahl (1979) failed to find that repeated reading improved tachistoscopic recognition of words, and neither Dowhower (1989) nor McFalls, Schwanenflugel, and Stahl (1996) found that fluencyoriented instruction improved children's response latency to words. Thus, fluency-oriented instruction seems to have salutary effects in a number of areas but not in the area that it was intended for, rapid recognition of isolated words.

\section{Prosody, Automaticity, and Comprehension}

Both the assisted and unassisted methods of fluency interventions have been generally effective in facilitating reading rate and accuracy. Given the amount of repetition or practice with print that they require on the part of learners, these results are not surprising. However, they also lead to improvements on measures of learners' comprehension. The following question then arises: Does this understanding develop simply from the amount of practice students undergo with regard to word recognition, or is there something more specific to their reading of connected text and their emerging sense of its relation to oral language that allows for this understanding to develop?

If comprehension were improved only by improved automatic word recognition, then teaching children to identify words faster would have an effect on comprehension. A number of studies have examined teaching children to say words faster (Fleisher et al., 1979-1980; Levy, Abello, \& Lysynchuk, 1997; Spring, Blunden, \& Gatheral, 1981). Although in all of these studies children's passage reading fluency improved, in none of these studies did their comprehension significantly differ from that of a control group. In these studies, children were taught to say the words in a list that they knew faster. In contrast, preteaching words that children did not know seems to improve comprehension (e.g., Blanchard, 1981; Tan \& Nicholson, 1997). Thus, it seems that more than speed of recognition is involved in the effects of repeated and assisted readings on comprehension.

Another source of information is the research on parsing or segmenting texts. Beginning with Cromer (1970), a number of researchers have found that presenting students with text segmented by phrase units seems to produce better comprehension than conventional text. This effect is especially pronounced for children who are slow but accurate readers (Cromer, 1970; O'Shea $\&$ Sindelar, 1983). Segmenting the text may provide the same cues to phrasal structure as prosody does in oral language (Schreiber, 1980, 1987). However, nearly all researchers studied the effects of segmenting text with older children, fourth grade and higher, a different population than we are concerned with. O'Shea and Sindelar (1983) were the only researchers we found who worked with primary-grade children. They found that segmented text produced better comprehension than conventional text, as measured by a maze-type cloze test. Being able to segment text by phrasal boundaries may improve comprehension in primary-grade children, but we are reluctant to infer from the results of one study that fluency instructional effects on comprehension are due to their effects on prosody.

Given that assisted and repeated reading and parsing of texts both seem to aid learners' comprehension, and speeded recognition of isolated words does not, we would argue that it is more than simply automaticity and accuracy that allow this understanding to develop. Further, the discussion surrounding prosody as a necessary component in children's ability to understand oral language and its role in language acquisition all add to the argument that prosody is equally necessary to developing an understanding of written text. Finally, given that fluent oral reading is considered to be expressive as well as quick and accurate and that prosodic features are, to a large extent, responsible for such expression, it is important to consider a definition of fluency that encompasses more than rate and accuracy.

\section{Directions for Future Research}

Fluency instruction seems to be a promising approach to teaching children in the confirmation and fluency stage of reading, especially those in late first and second grades, but also children with reading problems who are disfluent. Although the basic approaches have been around for over 30 years, there are many unanswered questions. We are still not sure of the role of repetitive reading, whether increasing the amount of reading done would have similar effects, what the effects are of reading texts at a range of difficulties, whether fluency instruction works by improving automatic word recognition or whether it effects perception of phrasal boundaries, and how does improved fluency affect comprehension. These are questions worth exploring.

These issues all relate to the larger notion of "practice." It has been argued that practice in reading is vital to develop as a reader (e.g., Berliner, 1981). But what kind of practice is needed? We know that time spent reading is an important variable in learning to read, but time spent reading what? Is reading difficult material 
more useful than reading easy material? Is reading the same material repeatedly as useful as reading new material? Does repeated reading lead to improved self-monitoring and correction? Are there different effects for oral and silent reading?

From this review, we have come to view fluency instruction as successful in improving the reading achievement of children at a certain point in their reading development. However, we have seen relatively little of this instruction in the schools. To help more readers move from labored decoding to the construction of meaning, we consider it to be important that educators integrate these techniques in the classroom more frequently.

\section{References}

Adams, M. J. (1990). Beginning to read: Thinking and learning about print. Cambridge, MA: MIT Press.

Allington, R. L. (1983). Fluency: The neglected reading goal. The Reading Teacher, 37, 556-561.

Anderson, R. C., Hiebert, E. F., Wilkinson, I. A. G., \& Scott, J. (1985). Becoming a nation of readers. Champaign, IL: National Academy of Education and Center for the Study of Reading.

Anderson, R. C., Wilson, P. T., \& Fielding, L. G. (1988). Growth in reading and how children spend their time outside of school. Reading Research Quarterly, 23, 285-303.

Bell, D. M., Markley, B. K., \& Yonker, R. J. (1990). The effect of repeated reading on elementary students' attitude toward reading. East Lansing, MI: National Center for Research on Teaching Learning. (ERIC Document Reproduction Service No. ED326844)

Berliner, D. C. (1981). Academic learning time and reading achievement. In J. T. Guthrie (Ed.), Comprehension and teaching: Research reviews (pp. 203-226). Newark, DE: International Reading Association.

Blanchard, J. S. (1981). A comprehension strategy for disabled readers in the middle school. Journal of Reading, 24, 331-336.

Blum, I. H., Koskinen, P. S., Tennant, N., Parker, E. M., Straub, M., \& Curry, C. (1995). Using audiotaped books to extend classroom literacy instruction into the homes of second-language learners (Reading Research Report No. 39). Athens, GA: National Reading Research Center.

Bohlen, L. (1988). Building fluency through repeated reading in the third grade. East Lansing, MI: National Center for Research on Teaching Learning. (ERIC Document Reproduction Service No. ED294158)

Carbo, M. (1978). Teaching reading with talking books. The Reading Teacher, 32, 267-273.

Carbo, M. (1981). Making books talk to children. The Reading Teacher, 35, 186-189.

Carver, R. P., \& Hoffman, J. V. (1981). The effect of practice through repeated reading on gain in reading ability using a computer-based instructional system. Reading Research Quarterly, 16, 374-390.

Chafe, W. (1988). Punctuation and the prosody of written language. Written Communication, 5, 396-426.

Chall, J. S. (1996a). Learning to read: The great debate (3rd ed.). New York: McGraw-Hill.

Chall, J. S. (1996b). Stages of reading development (2nd ed.). Fort Worth, TX: Harcourt-Brace.

Chall, J. S., Jacobs, V., \& Baldwin, L. (1990). The reading crisis. Cambridge, MA: Harvard University Press.

Chomsky, C. (1978). When you still can't read in third grade. After decoding, what? In S. J. Samuels (Ed.), What research has to say about reading instruction (pp. 13-30). Newark, DE: International Reading Association.

Clay, M. M. (1993). Reading recovery: A guidebook for teachers in training. Portsmouth, NH: Heinemann.

Clay, M. M., \& Imlach, R. H. (1971). Juncture, pitch, and stress as reading behavior variables. Journal of Verbal Learning and Verbal Behavior, 10, 133-139.
Cromer, W. (1970). The difference model: A new explanation for some reading difficulties. Journal of Educational Psychology, 61, 471-483.

Cunningham, A. E., \& Stanovich, K. E. (1991). Tracking the unique effects of print exposure in children: Associations with vocabulary, general knowledge, and spelling. Journal of Educational Psychology, 83, 264 274.

Cunningham, A. E., \& Stanovich, K. E. (1998). The impact of print exposure on word recognition. In J. Metsala \& L. Ehri (Eds.), Word recognition and beginning literacy (pp. 235-262). Mahwah, NJ: Erlbaum.

Dahl, P. R. (1979). An experimental program for teaching high speed word recognition and comprehension skills. In J. E. Button, T. Lovitt, \& T. Rowland (Eds.), Communications research in learning disabilities and mental retardation (pp. 33-65). Baltimore: University Park Press.

Dowhower, S. L. (1987). Effects of repeated reading on second-grade transitional readers' fluency and comprehension. Reading Research Quarterly, 22, 389-406.

Dowhower, S. L. (1989). Repeated reading: Theory into practice. The Reading Teacher, 42, 502-507.

Dowhower, S. L. (1991). Speaking of prosody: Fluency's unattended bedfellow. Theory in Practice, 30, 158-164.

Ehri, L. C. (1995). Phases of development in learning to read words by sight. Journal of Research in Reading, 18, 116-125.

Ehri, L. C. (1998). Grapheme-phoneme knowledge is essential for learning to read words in English. In J. L. Metsala \& L. C. Ehri (Eds.), Word recognition in beginning literacy (pp. 3-40). Mahwah, NJ: Erlbaum.

Eldredge, J. L. (1990). Increasing the performance of poor readers in the third grade with a group-assisted strategy. Journal of Educational Research, 84, 69-77.

Eldredge, J. L., \& Quinn, D. W. (1988). Increasing reading performance of low-achieving second graders with dyad reading groups. Journal of Educational Research, 82, 40-46.

Eldredge, J. L., Reutzel, D. R., \& Hollingsworth, P. M. (1996). Comparing the effectiveness of two oral reading practices: Round robin reading and the shared book experience. Journal of Literacy Research, 28, 201-225.

Elley, W. B. (2000). The potential of book floods for raising literacy levels. International Review of Education, 46, 233-255.

Evans, M. A., \& Carr, T. H. (1985). Cognitive abilities, conditions of learning and the early development of reading skill. Reading Research Quarterly, 20, 327-350.

Fleisher, L. S., Jenkins, J. R., \& Pany, D. (1979-1980). Effects on poor readers' comprehension of training in rapid decoding. Reading Research Quarterly, 15, 30-48.

Gardner, C. (1965). Experimental use of the impress method of reading rehabilitation. East Lansing, MI: National Center for Research on Teaching Learning. (ERIC Document Reproduction Service No. ED003838)

Gilbert, L. M., Williams, R. L., \& McLaughlin, T. F. (1996). Use of assisted reading to increase correct reading rates and decrease error rates of students with learning disabilities. Journal of Applied Behavior Analysis, 29, 255-257.

Hannah, A. M. (1994). The effects of repeated readings on the reading fluency and comprehension of second-grade, Chapter I students. Unpublished doctoral dissertation, University of Delaware.

Harris, A. J., \& Sipay, E. (1990). How to increase reading ability (10th ed.). White Plains, NY: Longman.

Heckelman, R. G. (1969). A neurological-impress method of remedialreading instruction. Academic Therapy Quarterly, 4, 277-282.

Heckelman, R. G. (1986). N. I. M. revisited. Academic Therapy, 21, 411-420.

Herman, P. A. (1985). The effect of repeated readings on reading rate, speech pauses, and word recognition accuracy. Reading Research Quarterly, 20, 553-565. 
Hoffman, J. (1987). Rethinking the role of oral reading. Elementary School Journal, 87, 367-373.

Holdaway, D. (1979). The foundations of literacy. Sydney, Australia: Ashton-Scholastic.

Hollingsworth, P. M. (1970). An experiment with the impress method of teaching reading. The Reading Teacher, 24, 112-114.

Hollingsworth, P. M. (1978). An experimental approach to the impress method of teaching reading. The Reading Teacher, 31, 624-626.

Homan, S., Klesius, P., \& Hite, S. (1993). Effects of repeated readings and nonrepetitive strategies on students' fluency and comprehension. Journal of Educational Research, 87, 94-99.

Hoskisson, K., \& Krohm, B. (1974). Reading by immersion: Assisted reading. Elementary English, 51, 832-836.

Johns, J. L. (1993). Informal reading inventories. DeKalb, IL: Communitech International.

Kintsch, W. (1998). Comprehension: A paradigm for cognition. Cambridge, England: Cambridge University Press.

Knupp, R. (1988). Improving oral reading skills of educationally handicapped elementary school-aged students through repeated readings. East Lansing, MI: National Center for Research on Teaching Learning. (ERIC Document Reproduction Service No. ED297275)

Koch, K. A. (1984). The effects of oral repeated reading on second grade students' oral reading accuracy, rate, and comprehension. Unpublished doctoral dissertation, Purdue University.

Koskinen, P. S., \& Blum, I. H. (1984). Repeated oral reading and the acquisition of fluency. In J. A. Niles \& L. A. Harris (Eds.), Changing perspectives on research in reading/language processing and instruction: Thirty Third yearbook of the National Reading Conference (pp. 183-187). Rochester, NY: National Reading Conference.

Koskinen, P. S., \& Blum, I. H. (1986). Paired repeated reading: A classroom strategy for developing fluent reading. The Reading Teacher, 40, $70-75$.

Koskinen, P. S., Wilson, R. M., \& Jensema, C. J. (1985). Closed-captioned television: A new tool for reading instruction. Reading World, 24(4), $1-7$.

Krashen, S. (2001). More smoke and mirrors: A critique of the National Reading Panel report on fluency. Phi Delta Kappan, 83, 119-123.

Labbo, L. D., \& Teale, W. H. (1990). Cross age reading: A strategy for helping poor readers. The Reading Teacher, 43, 363-369.

LaBerge, D., \& Samuels, S. J. (1974). Toward a theory of automatic information processing in reading. Cognitive Psychology, 6, 293-323.

Langford, K., Slade, B., \& Burnett, E. (1974). An examination of impress techniques in remedial reading. Academic Therapy, 9, 309-319.

Leinhardt, G., Zigmond, N., \& Cooley, W. (1981). Reading instruction and its effects. American Educational Research Journal, 18, 343-361.

Levy, B. A., Abello, B., \& Lysynchuk, L. (1997). Transfer from word training to reading in context: Gains in fluency and comprehension. Learning Disability Quarterly, 20, 173-188.

Levy, B. A., Barnes, L., \& Martin, L. (1993). Transfer of fluency across repetitions and across texts. Canadian Journal of Experimental Psychology, 47, 401-427.

Levy, B. A., Newell, S., Snyder, J., \& Timmins, K. (1986). Processing changes across reading encounters. Journal of Experimental Psychology: Learning, Memory, and Cognition, 12, 467-478.

Light, R. J., \& Pillemer, D. B. (1984). Summing up: The science of reviewing research. Cambridge, MA: Harvard University Press.

Marseglia, P. (1997). The effect of repeated readings on the fluency of high and low ability readers in a first grade class. East Lansing, MI: National Center for Research on Teaching Learning. (ERIC Document Reproduction Service No. ED405562)

Mathes, P. G., \& Fuchs, L. S. (1993). Peer-mediated reading instruction in special education resource rooms. Learning Disabilities Research and Practice, 8, 233-243.

McFalls, E. L., Schwanenflugel, P. J., \& Stahl, S. A. (1996). The influence of word meaning on the acquisition of a reading vocabulary in second grade children. Reading and Writing, 8, 235-250.

Mefferd, P. E., \& Pettegrew, B. S. (1997). Fostering literacy acquisition of students with developmental disabilities: Assisted reading with predictable trade books. Reading Research and Instruction, 36, 177-190.

Morgan, R., \& Lyon, E. (1979). "Paired reading": A preliminary report on a technique for parental tuition of reading-retarded children. Journal of Child Psychology and Psychiatry and Allied Disciplines, 20, 151-160.

Morris, D., \& Nelson, L. (1992). Supported oral reading with low achieving second graders. Reading Research and Instruction, 32, 49-63.

Mudre, L. H., \& McCormick, S. (1989). Effects of meaning-focused cues on underachieving readers' context use, self-corrections, and literal comprehension. Reading Research Quarterly, 24, 89-113.

National Reading Panel. (2000). Report of the subgroups: National Reading Panel. Washington, DC: National Institute of Child Health and Development.

Nell, V. (1988). Lost in a book: The psychology of reading for pleasure. New Haven, CT: Yale University Press.

Neuman, S. B., \& McCormick, S. (1995). Single-subject experimental research: Applications for literacy. Newark, DE: International Reading Association.

O'Shea, L. J., \& Sindelar, P. T. (1983). The effects of segmenting written discourse on the reading comprehension of low- and high-performance readers. Reading Research Quarterly, 18, 458-465.

O'Shea, L. J., Sindelar, P. T., \& O'Shea, D. (1985). The effects of repeated readings and attentional cues on reading fluency and comprehension. Journal of Reading Behavior, 17, 129-142.

O'Shea, L. J., Sindelar, P. T., \& O'Shea, D. (1987). The effects of repeated readings and attentional cues on the reading fluency and comprehension of learning disabled readers. Learning Disabilities Research, 2, 103109.

Perfetti, C. A. (1985). Reading ability. New York: Oxford University Press.

Perfetti, C. A. (1992). The representation problem in reading acquisition. In L. C. Ehri, R. Treiman, \& P. B. Gough (Ed.), Reading acquisition (pp. 145-174). Hillsdale, NJ: Erlbaum.

Person, M. E., \& Burke, D. M. (1984, October). Oral reading in the classroom. Paper presented at the annual meeting of the Northern Rocky Mountain Educational Research Association, Jackson Hole, WY. (ERIC Document Reproduction Service No. ED251796)

Ramunda, J. M. (1994). A cross-age reading program: Building fluency and comprehension. Unpublished master's thesis, Kean College. (ERIC Document Reproduction Service No. ED366940)

Rashotte, C. A., \& Torgesen, J. K. (1985). Repeated reading and reading fluency in learning-disabled children. Reading Research Quarterly, 20, $180-188$.

Rasinski, T. V. (1990a). Effects of repeated reading and listening-whilereading on reading fluency. Journal of Educational Research, 83, 147150 .

Rasinski, T. V. (1990b). Investigating measures of reading fluency. Educational Research Quarterly, 14, 37-44.

Rasinski, T. V., Padak, N., Linek, W., \& Sturtevant, B. (1994). Effects of fluency development on urban second-grade readers. Journal of Educational Research, 87, 158-165.

Read, C., \& Schreiber, P.A. (1982). Why short subjects are harder to find than long ones. In E. Wanner \& L. Gleitman (Eds.), Language acquisition: The state of the art (pp. 78-101). Cambridge, England: Cambridge University Press.

Reutzel, D. R., \& Hollingsworth, P. M. (1993). Effects of fluency training on second graders' reading comprehension. Journal of Educational Research, 86, 325-331.

Reutzel, D. R., Hollingsworth, P. M., \& Eldredge, J. L. (1994). Oral reading instruction: The impact on student reading development. Reading Research Quarterly, 29, 40-62. 
Richek, M. A., \& McTeague, B. K. (1988). The "Curious George" strategy for students with reading problems. The Reading Teacher, 42, 220-226.

Samuels, S. J. (1979). The method of repeated readings. The Reading Teacher, 32, 403-408.

Samuels, S. J. (1988). Decoding and automaticity: Helping poor readers become automatic at word recognition. The Reading Teacher, 41, 756760

Samuels, S. J., Schermer, N., \& Reinking, D. (1992). Reading fluency: Techniques for making decoding automatic. In S. J. Samuels \& A. E. Farstrup (Eds.), What research says about reading instruction (2nd ed., pp. 124-144). Newark, DE: International Reading Association.

Schreiber, P. A. (1980). On the acquisition of reading fluency. Journal of Reading Behavior, 12, 177-186.

Schreiber, P. A. (1987). Prosody and structure in children's syntactic processing. In R. Horowitz \& S. J. Samuels (Eds.), Comprehending oral and written language (pp. 243-270). New York: Academic Press.

Schreiber, P. A. (1991). Understanding prosody's role in reading acquisition. Theory into Practice, 30, 158-164.

Schreiber, P. A., \& Read, C. (1980). Children's use of phonetic cues in spelling, parsing, and-maybe-reading. Bulletin of the Orton Society, 30, 209-224.

Scruggs, T. E. (1987). The quantitative synthesis of single subject research: Methodology and validation. Remedial and Special Education, 8, 2433.

Simmons, D. C., Fuchs, L. S., Fuchs, D., Mathes, P., \& Hodge, J. P. (1995). Effects of explicit teaching and peer tutoring on the reading achievement of learning-disabled and low-performing students in regular classrooms. Elementary School Journal, 95, 387-408.

Spring, C., Blunden, D., \& Gatheral, M. (1981). Effect on reading comprehension of training to automaticity in word-reading. Perceptual and Motor Skills, 53, 779-786.

Stahl, S., Heubach, K., \& Cramond, B. (1997). Fluency-oriented reading instruction. Athens, GA: National Reading Research Center, U. S. Department of Education Office of Educational Research and Improvement Educational Resources Information Center.

Stahl, S. A., Jacobson, M. G., Davis, C. E., \& Davis, R. L. (1989). Prior knowledge and difficult vocabulary in the comprehension of unfamiliar text. Reading Research Quarterly, 24, 27-43.

Stahl, S. A., \& Murray, B. A. (1998). Issues involved in defining phonological awareness and its relation to early reading. In J. Metsala \& L. C. Ehri (Eds.), Word recognition in beginning literacy (pp. 65-88). Mahwah, NJ: Erlbaum.

Stanovich, K. E. (1980). Effects of explicit teaching and peer tutoring on the reading achievement of learning disabled and low-performing students in regular classrooms. Reading Research Quarterly, 16, 32-71.

Stanovich, K. E. (1984). The interactive-compensatory model of reading: A confluence of developmental, experimental, and educational psychology. Remedial and Special Education, 5(3), 11-19.

Stoddard, K., Valcante, G., Sindelar, P., O'Shea, L., \& Algozzine, P.
(1993). Increasing reading rate and comprehension: The effects of repeated readings, sentence segmentation, and intonation training. Reading Research and Instruction, 32, 53-65.

Strong, M. W., \& Traynelis-Yurek, E. (1983). Behavioral reinforcement within a perceptual-conditioning program of oral reading. East Lansing, MI: National Center for Research on Teaching Learning. (ERIC Document Reproduction Service No. ED233328)

Sutton, P. A. (1991). Strategies to increase oral reading fluency of primary resource students. East Lansing, MI: National Center for Research on Teaching Learning. (ERIC Document Reproduction Service No. ED335660)

Tan, A., \& Nicholson, T. (1997). Flashcards revisited: Training poor readers to read words faster improves their comprehension of text. Journal of Educational Psychology, 89, 276-288.

Taylor, B. M., Frye, B. J., \& Maruyama, G. M. (1990). Time spent reading and reading growth. American Educational Research Journal, 27, 351362 .

Tingstrom, D. H., Edwards, R. P., \& Olmi, D. J. (1995). Listening previewing in reading to read: Relative effects on oral reading fluency. Psychology in the Schools, 32, 318-327.

Topping, K. (1987). Paired reading: A powerful technique for parent use. The Reading Teacher, 40, 608-614.

Topping, K., \& Whitley, M. (1990). Participant evaluation of parenttutored and peer-tutored projects in reading. Educational Research, 32, $14-32$.

Turpie, J. J., \& Pastore, J. R. (1995). Using repeated readings to promote reading success in a heterogeneously grouped first grade. In K. A. Hinchman \& D. J. Leu (Eds.), Perspectives on literacy research and practice: Forty-fourth yearbook of the National Reading Conference (pp. 255-264). Chicago, IL: National Reading Conference.

Van Bon, W. H., Boksebeld, L. M., Font Freide, T. A., \& Van den Hurk, A. J. (1991). A comparison of three methods of reading-while-listening. Journal of Learning Disabilities, 24, 471-476.

van der Leij, A. (1981). Remediation of reading-disabled children by presenting text simultaneously to eye and ear. Bulletin of the Orton Society, 31, 229-243.

Vygotsky, L. (1978). Mind in society. Cambridge, MA: Harvard University Press.

Weinstein, G., \& Cooke, N. L. (1992). The effects of two repeated reading interventions on generalization of fluency. Learning Disability Quarterly, 15, 21-28.

Young, A. R., Bowers, P. G., \& MacKinnon, G. E. (1996). Effects of prosodic modeling and repeated reading on poor readers' fluency and comprehension. Applied Psycholinguistics, 17, 59-84.

Received November 30, 2001

Revision received June 7, 2002

Accepted June 8, 2002 